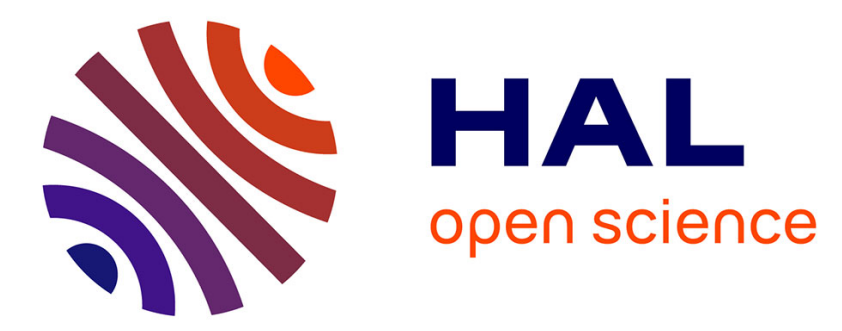

\title{
Evaluation of Inter-Hemispheric Characteristics of the Tropopause-Stratopause-Mesopause Over Sub-Tropical Regions
}

Som Sharma, Prashant Kumar, Rajesh Vaishnav, Chintan Jethva, Hassan Bencherif

\section{To cite this version:}

Som Sharma, Prashant Kumar, Rajesh Vaishnav, Chintan Jethva, Hassan Bencherif. Evaluation of Inter-Hemispheric Characteristics of the Tropopause-Stratopause-Mesopause Over Sub-Tropical Regions. Pure and Applied Geophysics, In press, 10.1007/s00024-017-1706-8 . hal-01634456

\section{HAL Id: hal-01634456 \\ https://hal.univ-reunion.fr/hal-01634456}

Submitted on 15 Nov 2017

HAL is a multi-disciplinary open access archive for the deposit and dissemination of scientific research documents, whether they are published or not. The documents may come from teaching and research institutions in France or abroad, or from public or private research centers.
L'archive ouverte pluridisciplinaire HAL, est destinée au dépôt et à la diffusion de documents scientifiques de niveau recherche, publiés ou non, émanant des établissements d'enseignement et de recherche français ou étrangers, des laboratoires publics ou privés. 


\title{
Evaluation of Inter-Hemispheric Characteristics of the
}

\section{Tropopause-Stratopause-Mesopause Over Sub-Tropical Regions}

\author{
Som Sharma, ${ }^{1}$ (D) Prashant Kumar, ${ }^{2}$ Rajesh Vaishnav, ${ }^{1}$ Chintan Jethva, ${ }^{1,3}$ and Hassan Bencherif ${ }^{4}$
}

\begin{abstract}
The transition regions in thermal structure viz. Tropopause, stratopause and mesopause play a vital role in the vertical coupling of the Earth's atmosphere. For the first time, inter-hemispheric characteristics of the transition regions over two subtropical regions are studied using temperature observations from the SABER onboard TIMED satellite and the ERA Interim reanalysis during year 2002 to 2015 . Results show that tropopause height is higher over Reunion Island $\left(21.11^{\circ} \mathrm{S}, 55.53^{\circ} \mathrm{E}\right)$ in the Southern Hemisphere ( $\mathrm{SH})$ as compared to Mt. Abu region $\left(24.59^{\circ} \mathrm{N}, 72.70^{\circ} \mathrm{E}\right)$ in the Northern Hemisphere $(\mathrm{NH})$. Temporal variation of tropopause temperature reveals a decreasing $(\sim 4 \mathrm{~K})$ trend from year 2002 to 2008 and beyond this, an increasing $(\sim 1.5 \mathrm{~K})$ trend is found in tropopause temperature. These features are reinforcing for Mesopause as compared to tropopause tem-perature. The $\mathrm{SH}$ shows stronger variations in Mesopause temperature ( $7 \mathrm{~K})$ compared to $\mathrm{NH}$ during year 2002 to 2008 . The occurrence frequency of mesopause and stratopause height shows that the maximum occurrence frequency $(\sim 60 \%)$ of mesopause at $\sim 100 \mathrm{~km}$ in $\mathrm{NH}$, while frequency is found to be $\sim$ $55 \%$ in the SH. Results show that stratopause (mesopause) is cooler (warmer) in $\mathrm{NH}$ as compared $\mathrm{SH}$. Moreover, Lomb Scargle Periodogram and wavelet transform techniques are used to inves-tigate the periodicity of mesopause, stratopause and tropopause temperatures and heights. Investigations revealed prominent annual oscillations in the tropopause and stratopause temperatures in both hemispheres. These findings will be of immense use for the vertical and interhemispheric atmospheric coupling studies.
\end{abstract}

\footnotetext{
1 Physical Research Laboratory, Ahmedabad 380009, India. E-mail: somkumar@prl.res.in; sharmasomkumar@gmail.com

2 Space Applications Center (ISRO), Ahmedabad 380015, India.

3 Department of Physics, Saurashtra University, Rajkot, India.

4 Laboratory of the Atmosphere and Cyclones (LACY), University of Réunion Island, Reunion, France.
}

\section{Introduction}

The Earth's atmosphere is classified in terms of regions, making up the vertical structure of the temperature field. These regions are termed the troposphere, stratosphere, mesosphere and thermosphere, while the boundaries between them are called the tropopause (about $\sim 16 \mathrm{~km}$ at low-latitudes, $\sim 12 \mathrm{~km}$ at mid-latitudes and $\sim 8 \mathrm{~km}$ at high-latitudes), stratopause ( $\sim 48 \mathrm{~km})$ and mesopause ( $\sim 85 \mathrm{~km})$, respectively. The tropopause is the boundary between convective (turbulent) and nonconvective (stable) regions, stratopause is joining stable to turbulent region and Mesopause is a transition region between the homosphere and heterosphere. Coupling between different regions of the atmosphere is very important to study as each and every region is intricately coupled with different regions, and this coupling is very complex (Gettelman and Forster 2002).

The tropopause, stratopause and mesopause play a vital role in the vertical coupling of the Earth's atmosphere. Height and temperature of these pauses is crucial in investigation of various processes taking place in the atmosphere (Sharma et al. 2006, 2012). Atmospheric waves that propagate upward are working as a coupler in different atmospheric regions by interacting with mean flow. Dunkerton (1997) showed that the tropical Quasi-Biennial Oscillation (QBO) is determined by joint forcing of gravity waves, Kelvin waves and by mixed Rossby-gravity waves. Planetary waves (PW) are very crucial in deciding dynamical state of the atmosphere. In the Northern hemisphere $(\mathrm{NH})$ winter, $\mathrm{PW}$ are influenced by air flowing over the mountain ridges and over continental land masses. PW propagates upwards and 
are affecting stratosphere, mesosphere and/or may break in these regions (e.g., McIntyre and Palmer 1983). In contrast to the NH, Southern Hemisphere (SH) is having lesser land mass and relatively less number of mountain ranges. Therefore, PW are weaker in SH, and hence weakly modulating stratosphere-mesosphere system than in the $\mathrm{NH}$; consequently southern polar vortex is relatively dormant (Thompson et al. 2002).

The tropopause is a changeover region between the convectively dominated troposphere and the radiatively controlled stratosphere (Gettelman and Forster 2002). Recently, the tropopause layer has received large attention due to stratospheric-tropospheric exchange of mass, water and chemical constituents between the two layers (Hoinka 1998). Randel et al. (2004) studied the interannual variations of stratospheric water vapor and its correlations with tropical tropopause temperatures over 1992-2003 using Halogen Occultation Experiment (HALOE) satellite measurements. Authors reported that QBO and El Nino Southern Oscillations (ENSO) have their influence on tropopause temperature. Hoinka (1998) studied global statistics of tropopause height, temperature, potential temperature, mixing ratio of water vapor, and zonal, meridional and vertical wind parameters for 15 years period (1979-93) derived from European Center for Medium range Weather Forecasting (ECMWF) reanalysis Interim (ERA-Interim) data by applying the thermal and dynamical definitions of the tropopause.

Tropopause height and its temperature play an important role in the transport between the stratosphere and the troposphere. It is crucial to properly quantify the transport between the tropical, subtropical, middle-latitude and over the Polar Regions which are having different processes and constituent characteristics. Danielsen (1968) studied upper tropospheric fronts and associated tropopause folds. Furthermore, different synoptic events, which are varying widely, and control the processes associated with irreversible transport, need further investigations. These are having influence on various processes such as wave transience, turbulence and convective transport (Sharma et al. 2012).

The stratospheric-tropospheric interactions and exchanges have been studied extensively in last decades (Appenzeller and Davies 1992; Baray et al. 1999; Meloen 2003; Hocking et al. 2007; Das 2009, Škerlak et al. 2014 and reference therein). Holton et al. (1995) presented a very exhaustive review on the features of dynamical, chemical and radiative coupling in the troposphere and stratosphere. Over the mid latitude regions, various studies were carried out on stratosphere-troposphere interactions and exchanges processes (e.g., Narayana Rao et al. 2008 and references therein). The tropical upwelling is an important feature of stratosphere-troposphere coupling as air enters the stratosphere primarily in the tropics. Tropical and sub-tropical tropopause and the chemical composition of air in these height ranges lay down the boundary condition for the global stratospheric composition. The stratospheric circulation is also significantly influenced by the tropical upwelling (Rosenlof 1995), and it can be inferred from the interpretations of minor constituents (Hall and Waugh 1997; Niwano et al. 2003 and references therein). During NH winter the tropical upwelling imposes comparatively larger yearly cycle in the lower stratosphere and is seen in form of a large annual cycle in the temperature of the tropopause region, which further influences seasonal cycle of stratospheric water vapour (e.g., Mote et al. 1996). Seasonality in the tropical upwelling could also result in stratospheric forcing induced by PW. The maximum forcing was found during September to November in the SH and during November to March in the NH (e.g., Yulaeva et al. 1994). Tropopause features have been studied extensively over the globe as it is rather easy to explore troposphere using ground-based instruments viz., MST radars, Lidars, Balloons, etc. Exploration of stratopause region is rather difficult from ground-based observations as balloons are limited by height coverage and MST radars are blind in this region and Rockets are limited to coastal coverage and are very sparse. From ground, Rayleigh lidars are very good but these are also limited to night-time clear weather condition observations. Space-borne instruments are able to provide global observations in these altitudes regions.

Stratosphere is one the important regions of the Earth's atmosphere and having very weak and/or no turbulence due to stable temperature structure. Ramaswamy et al. (2001) studied temperature trends 
in the stratosphere using lidar and rocket observations and showed the upper stratosphere is cooling at the rate of $\sim 1-2 \mathrm{~K} /$ decade and they further reported that the largest cooling of $\sim 3 \mathrm{~K} /$ decade occurred in the stratopause region. His finding paves the path to further explore and understand the processes that modulate stratopause region and to quantify variabilities associated with it. Stratopause is variable latitudinally and seasonally due to different physical processes. Tropical and sub-tropical latitude regions receive maximum energy from the Sun. Due to absorption of shortwave radiations by ozone, the stratopause is the warmest and found at height of $\sim 50 \mathrm{~km}$; in contrast to it over high latitude/polar regions there is poor/no solar insolation and, therefore, polar winter stratopause is sustained by gravity wave-driven diabatic descent at high latitudes (Hitchman et al. 1989 and reference therein). Kanzawa (1989) reported that in the undisturbed situations the stratopause in the polar region is at higher heights and relatively warmer than in midlatitudes. During sudden stratospheric warming events, PW amplitudes are large in the $\mathrm{NH}$ and stratopause is warm by up to $50 \mathrm{~K}$ (Labitzke 1977, 1981; Labitzke and Naujokat 2000). The temperature and height of the stratopause in the Polar Regions are maintained by GW and PW activity and high-latitude variability is governed by anticyclones. Inter-annual variability and comparison between the two hemispheres of the polar vortices was presented by Waugh et al. (1999). So far, there are no systematic long-term investigations on the sub-tropical stratopause region over both the hemispheres.

To understand the developments associated with neutral and electro-dynamical coupling, in depth investigation of the vertical structure of temperature in the mesosphere and lower thermosphere region is important but rather difficult. Explorations of the Mesopause region are rather more difficult and studies on it are reported using optical, radio, Lidar and satellite observations (e.g., Lübken and von Zahn 1991; She et al. 1993; Berger and von Zahn 1999; Walterscheid et al. 1999; She et al. 2004; Li et al. 2005a, b; Venkat Ratnam et al. 2010; Tang et al. 2014, and references therein). There are studies based on the observations of instability structures and GW characterization in the mesosphere, lower thermosphere and in the Mesopause region (covering the height range of $\sim 80-105 \mathrm{~km}$ ) (Li et al. $2005 \mathrm{a}, \mathrm{b})$. Tiny ripples are thought to be representative of instabilities in this region and have been reported in the Mesopause region using airglow observations (Taylor et al. 1997; Nakamura et al. 1999; Hecht 2004 and reference therein) and several $\mathrm{Na}$ lidar-based studies of Mesopause region have been reported (e.g., Williams et al. 2002; Liu et al. 2004; Prasanth et al. 2009; Sarkhel et al. 2009a, b; Sharma et al. 2006)). Venkat Ratnam et al. (2010) reported characteristics of Mesopause using Sounding of the Atmosphere using Broadband Emission Radiometry (SABER) onboard Thermosphere Ionosphere Mesosphere Energetics Dynamics (TIMED) satellite observations over a tropical region during 2002-2008 only and found that Mesopause is at $\sim 100 \mathrm{~km}$ altitude in the tropical region. Further, they found that the Mesopause temperature is decreasing with a rate of $\sim 0.72 \pm 0.05 \mathrm{~K} /$ year by analyzing SABER data during 2002-2008.

Limited studies are available over sub-tropical regions and on characteristics of stratosphere mesosphere interactions and exchange. This study is first of its kind using long time period satellite observations, to understand the features and characteristics of all the three important regions viz. Tropopause, stratopause and Mesopause covering both the hemispheres. The objective of this study was to fully scrutinize height and temperature structures in the tropo-strato-meso pause in the sub-tropical regions in both the hemispheres using $\sim 14$ years of SABER observations and ERA-Interim model reanalysis.

\section{Data Used}

\subsection{SABER Onboard TIMED}

In this study we have used SABER onboard TIMED satellite observed temperature from the year 2002 to 2015 in the altitude range of $20-110 \mathrm{~km}$ over two sub-tropical regions, $\mathrm{Mt}$. Abu $\left(24.59^{\circ} \mathrm{N}, 72.70^{\circ} \mathrm{E}\right)$ and Reunion $\left(21.11^{\circ} \mathrm{S}, 55.53^{\circ} \mathrm{E}\right)$ in the $\mathrm{NH}$ and in the $\mathrm{SH}$, respectively. SABER was launched during December 2001 and quality data are available since January 2002. The SABER measures kinetic 
temperature along with other parameters from $\sim 20$ to $\sim 150 \mathrm{~km}$ altitude range with very good latitudinal coverage from $\sim 80^{\circ} \mathrm{N}$ to $\sim 80^{\circ} \mathrm{S}$ (e.g., Russell et al. 1999; Yee et al. 1999; Xu et al. 2006, and references therein). SABER has orbital inclination of $73^{\circ}$ and looks the atmosphere perpendicular to the satellite velocity vector. SABER global viewing geometry provides a unique opportunity for the study of various processes and their role in coupling the troposphere-stratosphere-mesosphere-thermosphere system. Mertens et al. (2001) presented a method for extracting temperatures from $\mathrm{CO}_{2}$ emissions under conditions of nonlocal thermodynamic equilibrium, which is of concern above $\sim 70 \mathrm{~km}$ altitude region. A detailed description of the errors in SABERobserved temperature was provided by Remsberg et al. (2008). Fourteen years (2002-2015) of observations from SABER satellite overpasses over Mt $\mathrm{Abu}$, in the $\mathrm{NH}$, and over Reunion in the $\mathrm{SH}$, within $\pm 5^{\circ}$ in latitudinal and longitudinal grid have been employed in the present study. From the monthly temperature profiles stratopause and Mesopause temperature and height have been extracted. Furthermore, we have applied Lomb Scargle Periodogram (LSP) (Lomb 1976; Scargle 1982). This method can be used for unevenly spaced data sets (Press et al. 1992) also. The LSP method weights the data on a per-point basis, instead of per-time basis (Luo et al. 2002). Furthermore, to have better insight of periodicities with simultaneous localization in time and frequency domain, we have applied wavelet analysis techniques to investigate features in the temperatures and heights of the tropo-strato-mesopauses over both the regions.

\subsection{ERA-Interim Reanalysis}

As SABER observations are very good above $\sim 20 \mathrm{~km}$, for the study of Tropopause characteristics we have used ERA Interim Reanalysis data set over both the regions, Mt. Abu and Reunion. ERA-Interim is a third-generation reanalysis and provides much improved atmospheric data set as compared to ERA-40 (Dee et al. 2011). A vast amount of quality data obtained from surface measurements, radiosonde observations along with aircraft and satellite observations are introduced in data assimilation system of ERA-Interim reanalysis. Six hourly ERA-Interim data are available at 00, 06, 12 and 18 UTC. The horizontal resolution of the ERA-Interim fields is 0.70 with total 37 vertical hybrid levels. Kumar et al. (2015) compared three global model analyses over Indian regions.

\section{Results and Discussions}

The objective of this study was to understand the variability of Tropopause, stratopause and Mesopause height and temperature in both hemispheres at Mt. Abu and Reunion Island over sub-tropical regions. For this purpose, temporal variations of SABER observation during January 2002 to September 2015 are studied extensively. The altitude-temperature profile from ERA Interim reanalyses (below $20 \mathrm{~km}$ ) and SABER observations (above $20 \mathrm{~km}$ ) are shown in Fig. 1, which demonstrates mean monthly variations of temperature from January to December with $10 \mathrm{~K}$ shift along $x$-axis for better clarity. The mean height of Tropopause, stratopause and Mesopause are $\sim 17, \sim 46$ and $98 \mathrm{~km}$, respectively, over Mt. Abu region in the $\mathrm{NH}$; at these heights of pauses, value of temperature is around 195, 260 and $180 \mathrm{~K}$, respectively. Chandra et al. (2005) and Sharma et al. (2006, 2012) also reported mean stratopause height and temperature, $\sim 48 \mathrm{~km}$ and $271 \mathrm{~K}$, respectively, using Rayleigh Lidar observations over Mt. Abu. Over Reunion Island the mean height of Tropopause, Stratopause and Mesopause are $\sim 16, \sim 47$ and $\sim 98 \mathrm{~km}$, respectively. Rayleigh Lidar-based study by Sivakumar et al. (2011) revealed mean Stratopause height and temperature in the range of $\sim 44-52 \mathrm{~km}$ and $\sim 265-270 \mathrm{~K}$, respectively, over Reunion Island. As compared to NH, Tropopause height is slightly higher in the $\mathrm{SH}$ over Reunion Island while no noteworthy changes are found in stratopause and mesopause heights in these two hemispheric regions. Cooler ( $\sim 3 \mathrm{~K})$ Mesopause is noticed over Mt. Abu in the month of February as compared to Reunion Island.

Temporal variations of height and temperature during the period 2002-2015 are shown in Fig. 2. A very diminutive increasing trend in mesopause and stratopause height is seen in selected time period, 
(a) Mt. Abu

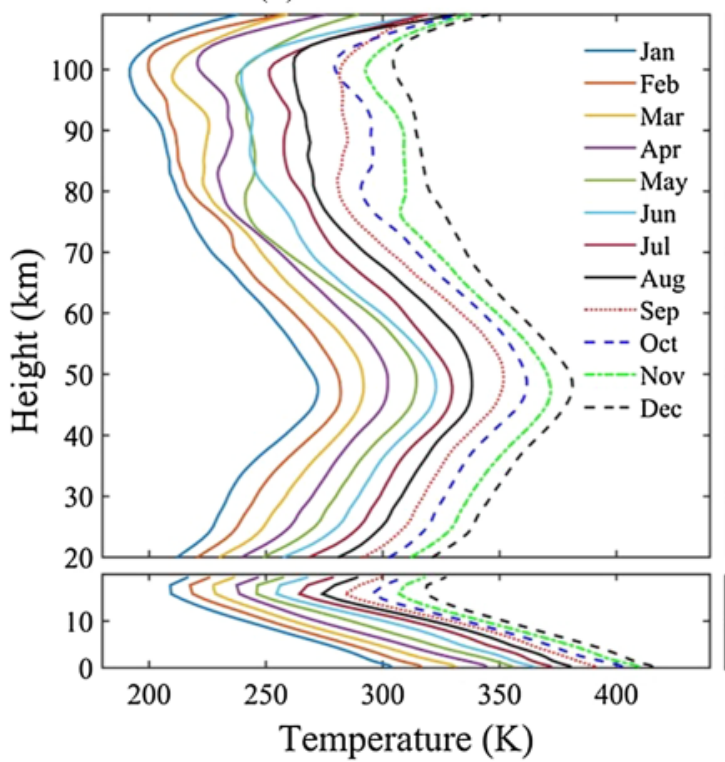

(b) Reunion Island

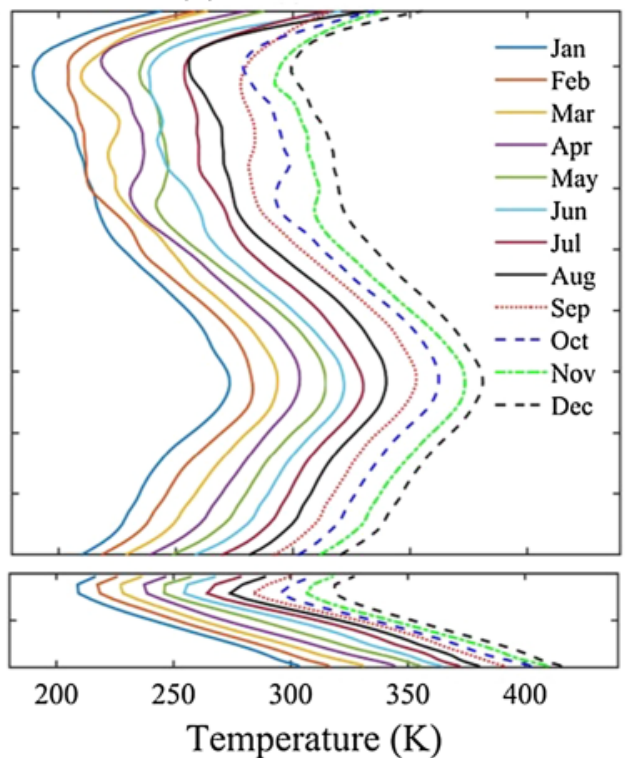

Figure 1

Monthly temperature profiles from, (1) ERA-Interim reanalyses from surface to $20 \mathrm{~km}$ and (2) SABER observations from 20 to $110 \mathrm{~km}$ over Mt. Abu and Reunion Island regions. The successive profiles are offset by $10 \mathrm{~K}$

whichis $\sim 1$ and $0.5 \mathrm{~km}$ for mesopause and Stratopause, respectively, in the past 14 years. No significant changes are found in Tropopause height during this period (figure not shown). Somewhat more variations are seen in Mesopause height in the $\mathrm{NH}$ as compared to $\mathrm{SH}$, which are $\sim 1 \mathrm{~km}$ and $0.3 \mathrm{~km}$ over Mt. Abu and Reunion Island, respectively. Temporal variation of temperature shows a very interesting trend, which is decreasing from year 2002 to 2008 and beyond this period, an increasing trend is found in temperature at different altitudes. Venkat Ratnam et al. (2010) have also reported a decreasing trend in the Mesopause height during 2002-2008 using SABER observations. These features are reinforcing for mesopause and stratopause as compared to Tropopause temperature. The difference between stratopause and mesopause temperature for years 2002 and 2008 are $\sim 4 \mathrm{~K}$, while increasing trend $(\sim 1.5 \mathrm{~K})$ is observed during year 2009 to 2015 over Mt. Abu region (Table 1). As compared to $\mathrm{NH}$, Reunion Island in SH shows stronger variations in Mesopause temperature $(\sim 7 \mathrm{~K})$ during years 2002 to 2008, while changes in Tropopause are not substantial in this period. Interestingly, results infer that Mt. Abu and Reunion Island show a cooling trend in Mesopause; this cooling trend is stronger in the $\mathrm{SH}(-0.14 \mathrm{~K} /$ year $)$ as compared to $\mathrm{NH}$ $(-0.07 \mathrm{~K} /$ year). Moreover, we found that Mesopause cooling over Reunion Island is nearly $50 \%$ times extra than Mt. Abu during year 2002 to 2008, and slightly more warming trend $(0.1 \mathrm{~K} /$ year $)$ is seen in year 2009 to 2015 . In the stratosphere, NH shows a cooling trend $(\sim-0.5 \mathrm{~K})$ in past 14 years. Interestingly, Reunion Island continuously shows a cooling trend while Mt. Abu shows cooling in years 2002 to 2008 and very small warming in years 2009 to 2015 . Overall, we found that SH has a more cooling tendency in mesopause and stratopause as compared to $\mathrm{NH}$ in the past decade.

Figure 3 shows the occurrence frequency of the mesopause and stratopause height and temperature during year January 2002 to September 2015. It shows that the maximum occurrence frequency ( $\sim 60 \%$ ) of the Mesopause height is $\sim 100 \mathrm{~km}$ in both the hemispheres, while frequency is higher in $\mathrm{NH}$ as compared to $\mathrm{SH}$ at this altitude. But at $95 \mathrm{~km}$, occurrence frequency is more in Reunion Island as compared to Mt. Abu. These results reveal that 
Mt. Abu

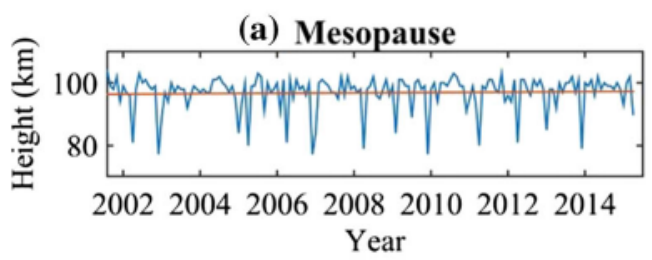

(b) Stratopause
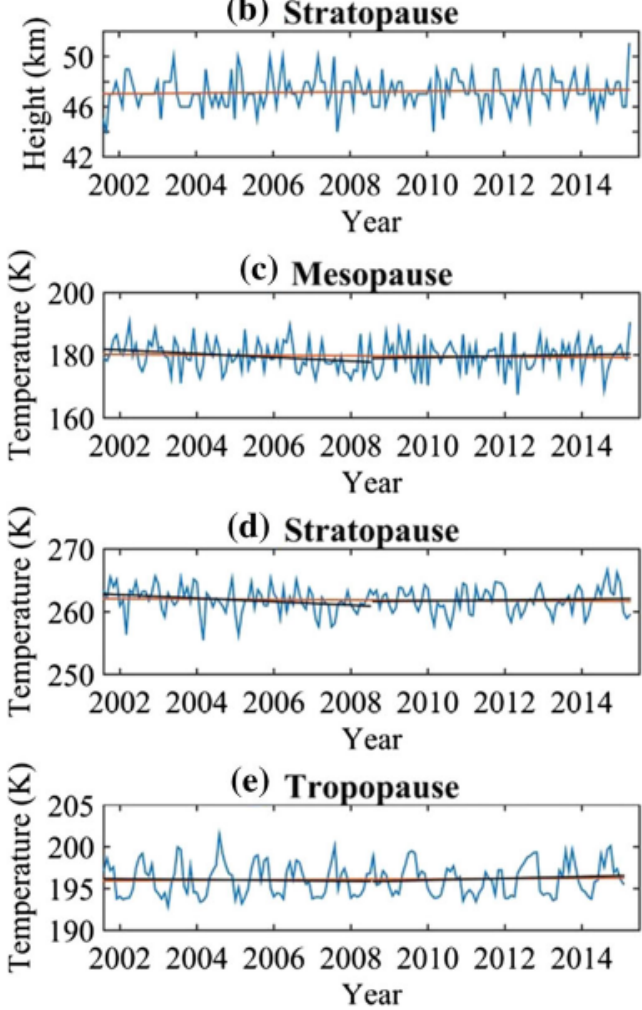

Reunion Island

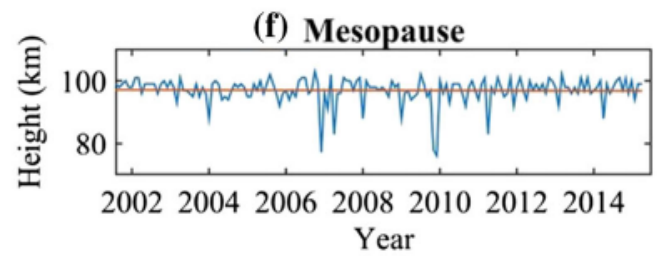

(g) Stratopause

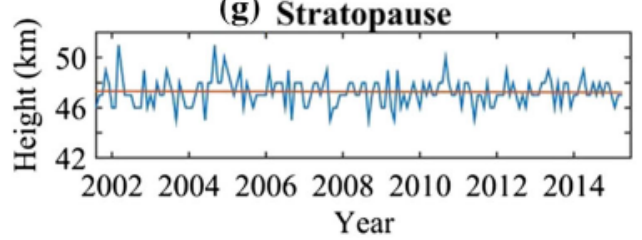

(h) Mesopause
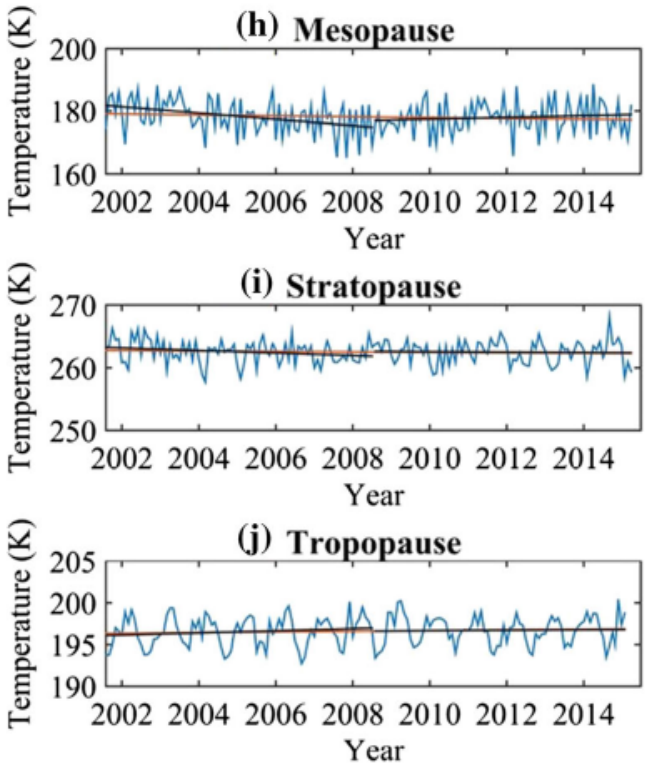

Figure 2

Temporal variation of: a Mesopause and $\mathbf{b}$ stratopause height, and $\mathbf{c}$ mesopause, $\mathbf{d}$ stratopause, and $\mathbf{e}$ tropopause temperature retrieved from SABER satellite over Mt. Abu region during January 2002 to September 2015. Temporal variation of $\mathbf{f}$ mesopause and $\mathbf{g}$ stratopause height, and $\mathbf{h}$ mesopause, $\mathbf{i}$ stratopause, and $\mathbf{j}$ tropopause temperature over Reunion Island for same period. Orange and black line shows best curve fitting using linear regression

Mesopause height is greater in $\mathrm{NH}$ compared to $\mathrm{SH}$. The Mesopause occurrence frequency is less than $5 \%$ below altitude of $95 \mathrm{~km}$ in both the hemispheres. Stratopause height occurrence frequency lies within 44-50 km; in which stratopause mostly exist between the altitude range of 46 and $48 \mathrm{~km}$. Sivakumar et al. (2011) have also found stratopause height between 44 and $52 \mathrm{~km}$ using ground-based Rayleigh Lidar observations. In addition to Mesopause and stratopause height, temperature values at these heights are also shown in Fig. 3. At the Mesopause, mostly temperature lies between 175 and $185 \mathrm{~K}$. It is interesting to notice here that Mesopause occurrence are less in the $\mathrm{NH}$ for low-temperature range (165-175 K) and more for high-temperature range (180-190 K), which shows that Mesopause temperature is warmer in the $\mathrm{NH}$ as compared to the SH. However, stratopause occurrences are more at lowtemperature range $(257-261 \mathrm{~K})$ in the $\mathrm{NH}$ and less at high-temperature range as compared to the $\mathrm{SH}$. These patterns show that the stratopause is cooler; Mesopause is warmer, in the $\mathrm{NH}$ as compared to the $\mathrm{SH}$. 
Table 1

Temperature difference between SABER observed and atmospheric models simulated temperature over Mt. Abu and Reunion Island

\begin{tabular}{|c|c|c|c|c|c|c|c|c|c|c|c|c|c|c|c|}
\hline \multirow[t]{3}{*}{ Month } & \multicolumn{6}{|c|}{ Mt. Abu } & \multicolumn{6}{|c|}{ Reunion Island } & \multicolumn{3}{|c|}{ Temperature Difference (K) } \\
\hline & \multicolumn{2}{|c|}{ Mesopause } & \multicolumn{2}{|c|}{ Stratopause } & \multicolumn{2}{|c|}{ Tropopause } & \multicolumn{2}{|c|}{ Mesopause } & \multicolumn{2}{|c|}{ Stratopause } & \multicolumn{2}{|c|}{ Tropopause } & \multicolumn{3}{|c|}{ Mt. Abu-Reunion Island } \\
\hline & $\begin{array}{l}\text { S-M } \\
(\mathrm{K})\end{array}$ & $\begin{array}{l}\text { S-C } \\
(\mathrm{K})\end{array}$ & $\begin{array}{l}\text { S-M } \\
(\mathrm{K})\end{array}$ & $\begin{array}{l}\text { S-C } \\
\text { (K) }\end{array}$ & $\begin{array}{l}\text { S-M } \\
(\mathrm{K})\end{array}$ & $\begin{array}{l}\text { S-C } \\
\text { (K) }\end{array}$ & $\begin{array}{l}\text { S-M } \\
(\mathrm{K})\end{array}$ & $\begin{array}{l}\text { S-C } \\
\text { (K) }\end{array}$ & $\begin{array}{l}\text { S-M } \\
(K)\end{array}$ & $\begin{array}{l}\text { S-C } \\
(\mathrm{K})\end{array}$ & $\begin{array}{l}\text { S-M } \\
(\mathrm{K})\end{array}$ & $\begin{array}{l}\text { S-C } \\
(\mathrm{K})\end{array}$ & Mesopause & Stratopause & Tropopause \\
\hline Jan & 11.7 & -9.3 & -3.1 & -2.6 & -5.0 & -6.4 & 0.9 & -7.9 & -3.1 & -4.0 & -7.5 & -7.4 & 2.0 & -0.9 & 4.2 \\
\hline Feb & 11.3 & -8.6 & -5.9 & -6.0 & -6.7 & -8.0 & 5.7 & -4.8 & -5.4 & -4.9 & -8.3 & -7.9 & -1.9 & -1.0 & 3.2 \\
\hline Mar & 11.2 & -5.7 & -8.9 & -6.8 & -6.8 & -8.6 & 5.1 & -7.1 & -7.5 & -4.8 & -7.4 & -7.2 & 0.9 & -1.5 & 2.2 \\
\hline Apr & 10.3 & -3.9 & -9.5 & -6.8 & -5.8 & -8.4 & 5.5 & -9.5 & -8.2 & -4.0 & -5.6 & -6.4 & 2.6 & -0.8 & 1.3 \\
\hline May & 16.5 & 3.1 & -5.1 & -3.9 & -7.1 & -10.0 & 15.0 & -3.4 & -4.7 & -1.1 & -3.8 & -5.5 & 1.5 & 0.5 & -1.8 \\
\hline Jun & 8.7 & -4.4 & -3.4 & -4.1 & -8.6 & -11.0 & 6.8 & -12.9 & -3.3 & -2.4 & -4.9 & -6.9 & 2.8 & 0.9 & -2.4 \\
\hline Jul & 11.7 & -1.1 & -4.1 & $-4-.5$ & -9.6 & -11.5 & 12.2 & -6.8 & -3.1 & -2.7 & -5.2 & -6.7 & 0.1 & -0.4 & -3.2 \\
\hline Aug & 8.5 & -3.6 & -5.0 & -4.7 & -10.6 & -11.6 & 4.3 & -13.3 & -3.6 & -5.8 & -5.5 & -6.3 & 5.2 & -1.6 & -4.0 \\
\hline Sep & 15.4 & 2.5 & -3.1 & -3.6 & -10.9 & -10.9 & 12.8 & -1.4 & -3.0 & -3.8 & -4.8 & -5.7 & 1.7 & -0.8 & -4.8 \\
\hline Oct & 7.4 & -7.5 & -4.3 & -4.5 & -8.7 & -8.8 & 2.8 & -7.9 & -4.7 & -5.9 & -4.3 & -5.5 & 0.8 & -0.7 & -3.0 \\
\hline Nov & 12.6 & -6.0 & -3.6 & -3.1 & -6.6 & -7.2 & 6.4 & -2.7 & -3.0 & -6.0 & -4.6 & -5.5 & -0.8 & -1.6 & -0.5 \\
\hline Dec & 15.3 & -5.2 & -3.7 & -4.4 & -5.4 & -6.4 & 2.7 & -5.5 & -4.7 & -7.6 & -6.0 & -6.5 & 4.0 & 0.1 & 2.3 \\
\hline
\end{tabular}

(a)

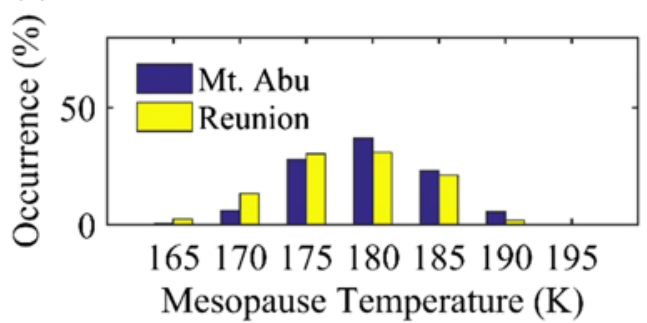

(b)

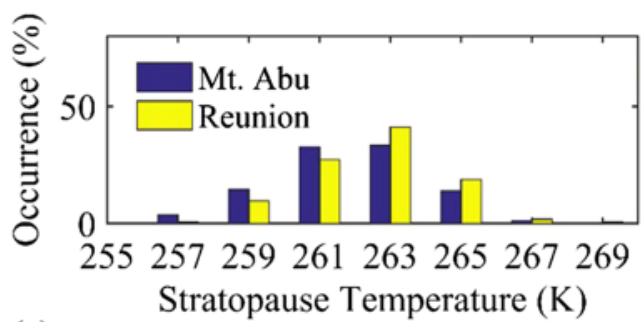

(c)

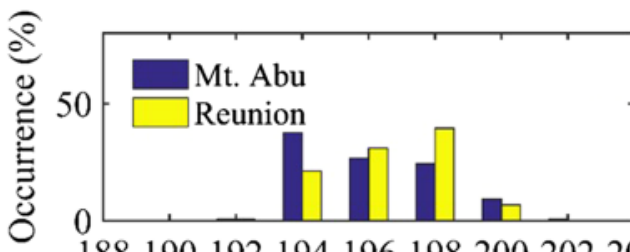

188190192194196198200202204

Tropopause Temperature $(\mathrm{K})$ (d)

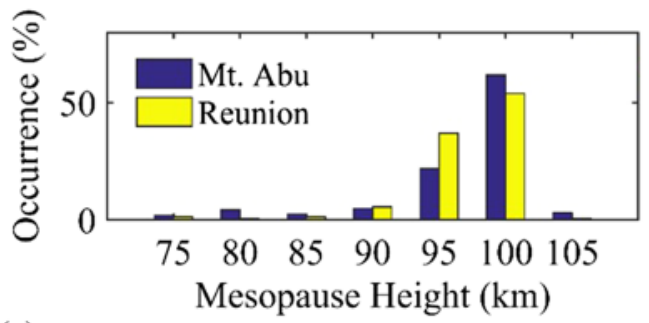

(e)

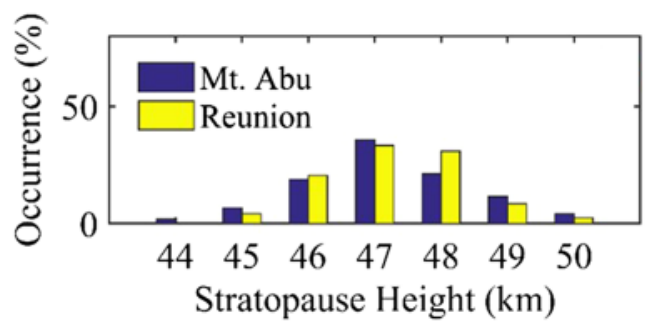

Figure 3

Occurrence frequency of: a mesopause and $\mathbf{b}$ stratopause temperature from SABER satellite, and $\mathbf{c}$ tropopause temperature from ERA-interim. d mesopause and e stratopause height from SABER satellite over Mt. Abu and Reunion Island 
Monthly statistics of the Mesopause and stratopause temperature and height for Mt. Abu and Reunion Island are shown in Fig. 4. The mean Mesopause temperature is $\sim 179.7$ and $178.1 \mathrm{~K}$ over Mt. Abu and Reunion Island, respectively. The maximum and minimum values of the Mesopause temperature are nearly 190.7 (188.7) $\mathrm{K}$ in September and 167.4 (165.1) $\mathrm{K}$ in October (April) over Mt. Abu (Reunion Island). Value of median is higher $(\sim 2 \mathrm{~K})$ over the $\mathrm{NH}$ as compared to the $\mathrm{SH}$. Both
Mt. Abu

(a) Mesopause

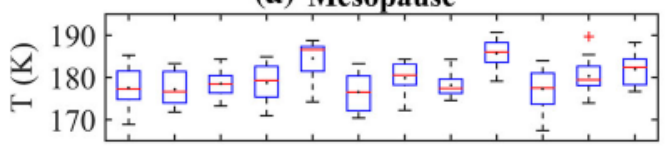

(b) Stratopause

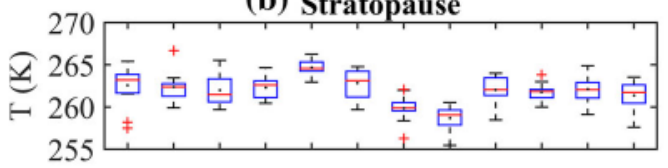

(c) Tropopause

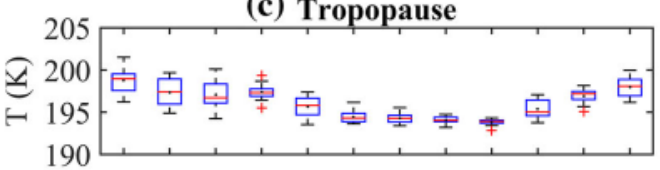

(d) Mesopause

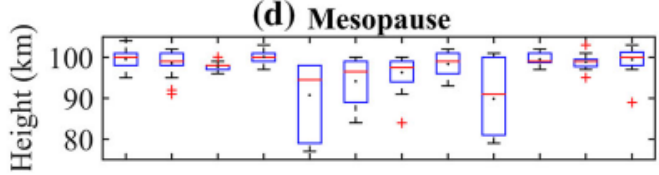

(e) Stratopause

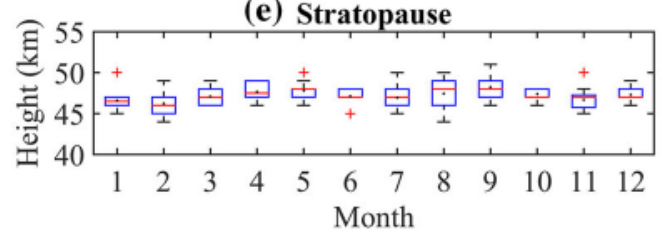

Reunion Island

(f) Mesopause

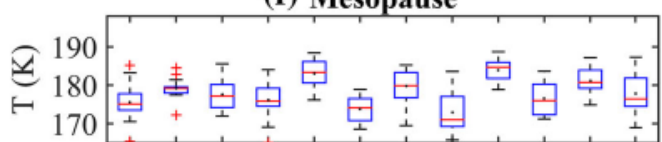

(g) Stratopause

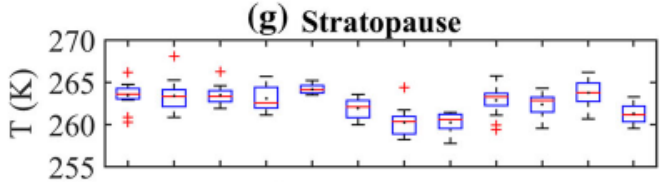

(h) Tropopause

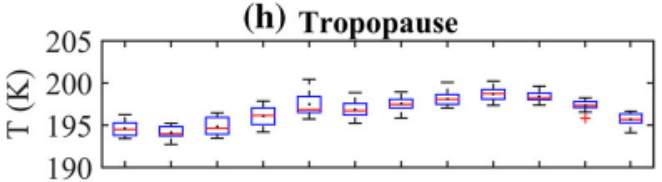

(i) Mesopause

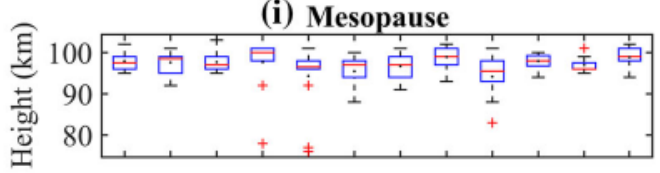

(j) Stratopause

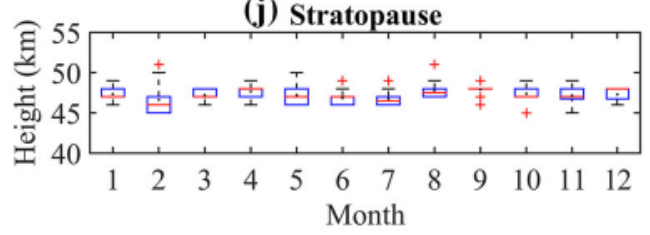

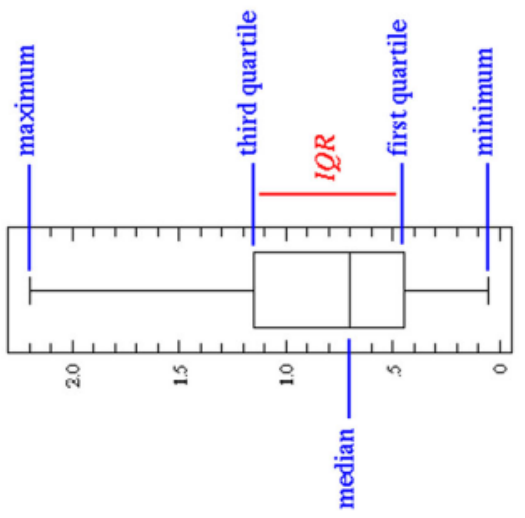

Figure 4

Box plot shows: a Mesopause and b stratopause temperature from SABER satellite, $\mathbf{c}$ tropopause temperature from ERA-interim, and d mesopause and e stratopause height from SABER satellite over Mt. Abu region during January 2002 to September 2015. f Mesopause and $\mathbf{g}$ stratopause temperature from SABER satellite, $\mathbf{h}$ tropopause temperature from ERA-interim, and $\mathbf{i}$ mesopause and $\mathbf{j}$ stratopause height from SABER satellite over Reunion Island during same period. Explanation of symbols and marks of box plot are also shown here 

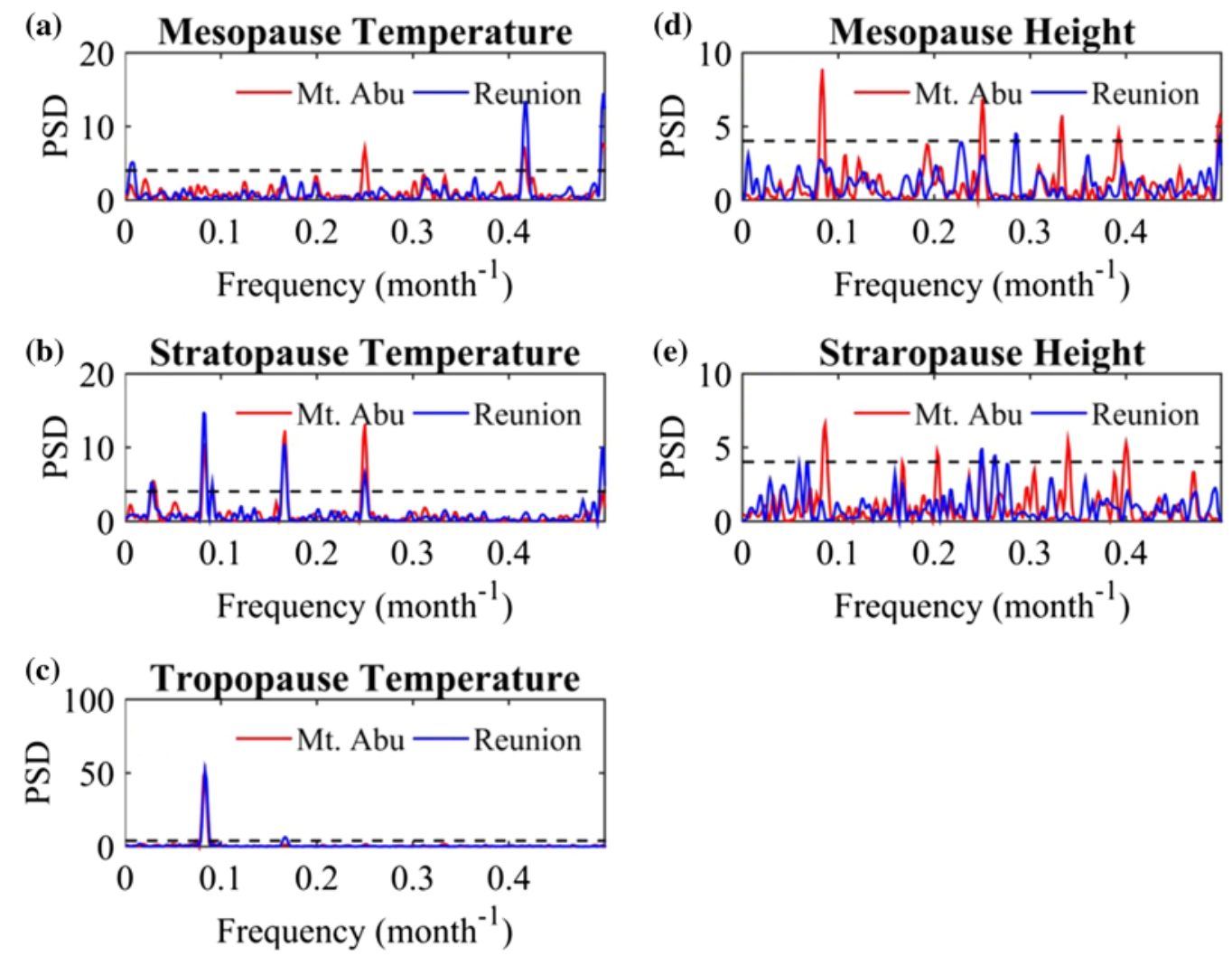

Figure 5

Lomb Scargle periodograms for: a mesopause and b stratopause from SABER satellite and $\mathbf{c}$ tropopause temperature from ERA-interim over Mt. Abu and Reunion Island region. $\mathbf{d}$ mesopause and e stratopause height from SABER satellite. The black dotted line shows significant level at $95 \%$ confidence interval

the hemispheres show the high value of mean temperature in the months of May and September. Mean stratopause temperature is also the maximum in the month of May in both hemispheres. Yearly mean stratopause temperature is somewhat more $(\sim 1 \mathrm{~K})$ in the $\mathrm{SH}$ against $\mathrm{NH}$; moreover, the Tropopause temperature is also higher in Reunion Island. The Tropopause temperature is less in February over NH and August-September in the SH. The maximum and minimum values of Mesopause height are $\sim 102$ $(\sim 101) \mathrm{km}$ in January (March) and $79(\sim 77)$ $\mathrm{km}$ in May, respectively, over Mt. Abu (Reunion Island) in the $\mathrm{NH}(\mathrm{SH})$. Mean value of the Mesopause height reaches up to $\sim 100 \mathrm{~km}$ in the month of April and minimum in the month of September $(\sim 90 \mathrm{~km})$ over Mt. Abu region, while maximum value of mean is $\sim 98 \mathrm{~km}$ over Reunion Island. Median value of the Mesopause height is little higher in the $\mathrm{NH}$ as compared to the SH. No major variations are seen in the stratopause height in both the hemispheres.

Moreover, we also investigate the periodicity of the mesopause, stratopause and tropopause temperatures and heights using Lomb Scargle Periodogram (LSP) and wavelet transform techniques. Figure 5 shows annual oscillations in tropopause and stratopause temperature, but these oscillations do not exist in mesopause over both hemispheres. Moreover, stratopause temperature shows quarterly oscillations, stronger in $\mathrm{NH}$, are also observe in Mesopause. Quarterly oscillations in Mesopause temperature are significant over Mt. Abu. Figure shows that at higher altitude oscillations are of lower period. Mesopause and stratopause height show strong annual oscillation in both hemispheres. It is interesting to note here that small period oscillations are more significant in Mesopause height as compared to Stratopause height. 

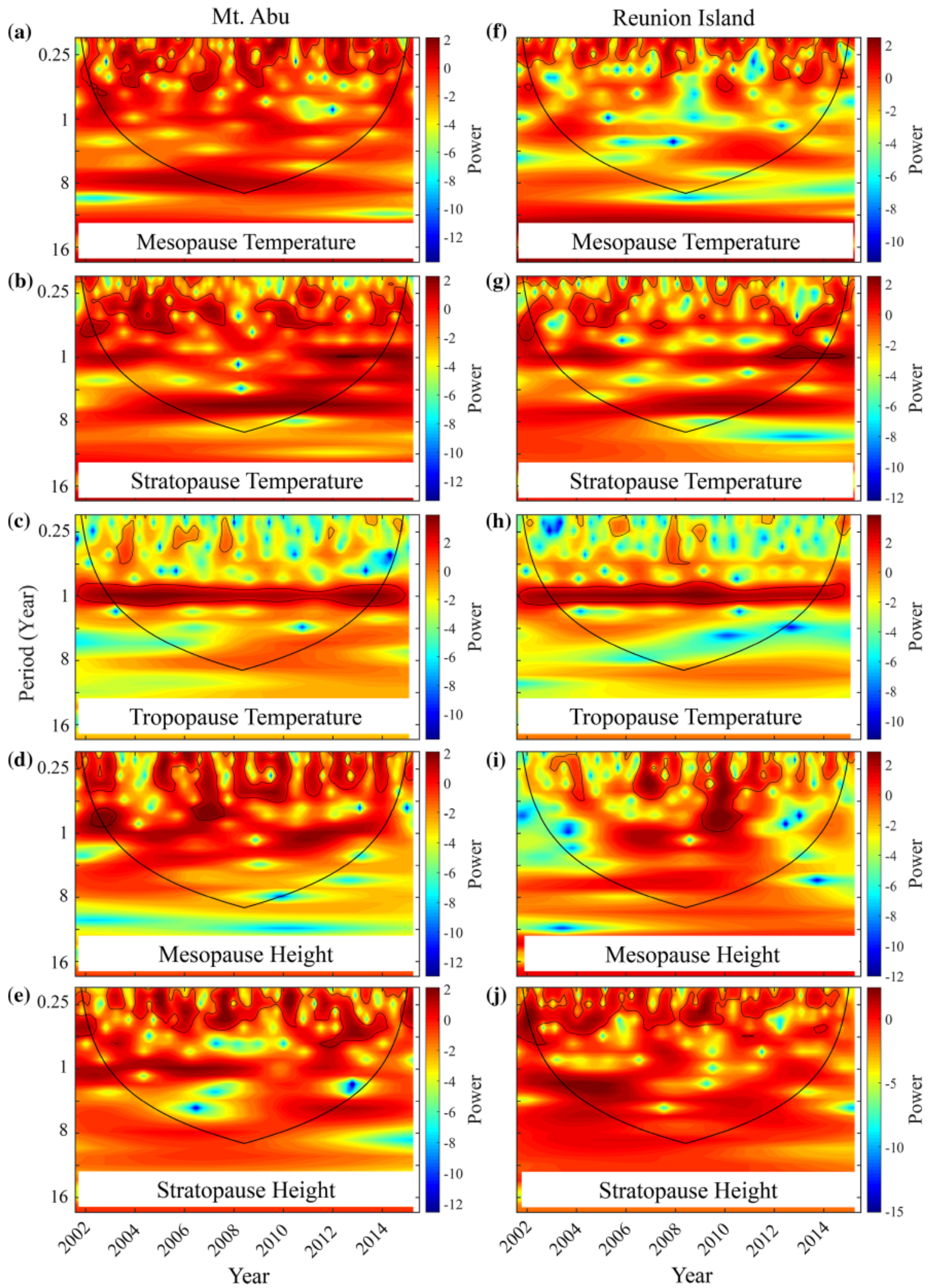
Figure 6

A continuous Wavelet transform of: a mesopause and $\mathbf{b}$ stratopause temperature from SABER satellite, $\mathbf{c}$ tropopause temperature from ERA-Interim, and d mesopause and e stratopause height from SABER satellite over Mt. Abu region during January 2002 to September 2015. f mesopause and $\mathbf{g}$ stratopause temperature from SABER satellite, $\mathbf{h}$ tropopause temperature from ERA-interim, and $\mathbf{i}$ mesopause and $\mathbf{j}$ stratopause height from SABER satellite over Reunion Island during same period. Black line in the contour plot shows cone of confidence

Wavelet transform method suggests that quarterly periodicity of Mesopause and Stratopause is more significant over Mt. Abu as compared to Reunion Island (Fig. 6). Both hemispheres show strong annual oscillations for Tropopause temperature. During year 2010, annual oscillations are very strong over Reunion Island. Similar to Stratopause and Mesopause temperature wavelet-based oscillations, Stratopause and Mesopause height show quarterly oscillations.

Figure 7 shows the Tropopause, Stratopause and Mesopause monthly temperature variations over Mt. Abu region and Reunion Island. Figure 7a shows that the Mass Spectrometer and Incoherent Scatter Radar Extended (MSISE-90) temperature is lower than the COSPAR International Reference Atmosphere

(a) Abu

(a) Mesopause temperature

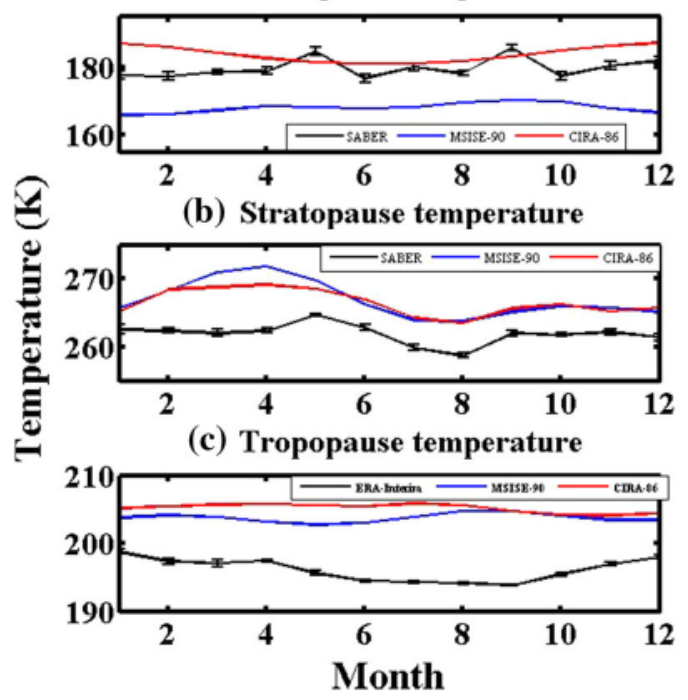

(CIRA-86) and SABER-observed Mesopause temperature. During the months of May and September Mesopause temperature observed from the SABER is more than the CIRA-86 temperature over Mt. Abu region. Mesopause temperature extracted from CIRA-86 reveals decreasing tendency from January to July and later slightly increases till December month. Figure 7d shows Mesopause variations extracted from CIRA-86 and MSISE-90 over Reunion Island; and shows similar variations as observed over Mt. Abu. It should be noted that the Mesopause temperature (CIRA-86) is higher than Mesopause temperature from SABER. MSISE-90 and CIRA-86 reveal a weak anti-correlation over Mt. Abu and Reunion Island. The variations of stratopause temperature over Mt. Abu region are shown in Fig. 7b. We found that the model-derived Stratopause temperature is higher than SABER-observed temperature in the Stratopause. Similar characteristic are found over Reunion Island and given in Fig. 7e. The difference in CIRA-86 and MSISE-90 Stratopause temperature is high over Reunion Island as compared to Mt. Abu. A maximum Stratopause temperature ia observed from MSISE-90 during month of April. Stratopause temperature from CIRA-86 is higher

Reunion Island
(d) Mesopause temperature

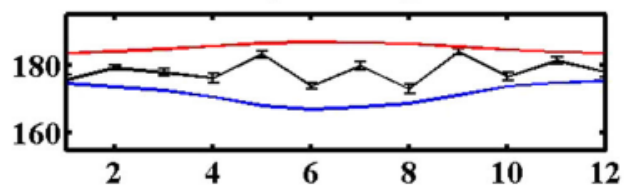

(e) Stratopause temperature

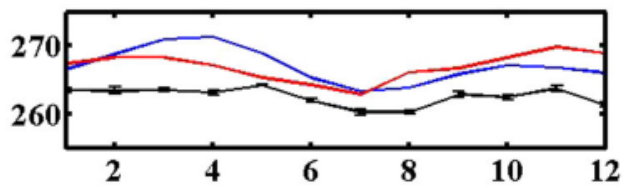

(f) Tropopause temperature

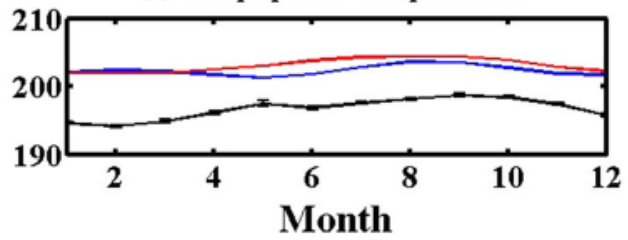

Figure 7

Temporal variation of mean: a mesopause and $\mathbf{b}$ stratopause temperature retrieved from SABER satellite, and $\mathbf{c}$ tropopause temperature from ERA-Interim reanalysis over Mt. Abu region. Temporal variations of mean, $\mathbf{d}$ mesopause and $\mathbf{e}$ stratopause temperature retrieved from SABER satellite, and $\mathbf{f}$ tropopause temperature from ERA-interim reanalysis over Reunion Island region 
during February to May over Mt. Abu region than Reunion Island, and from July to December, it is higher over Reunion Island as compared to Mt. Abu region. The stratopause temperature observed from the SABER shows a similar pattern over both the regions and the coolest Stratopause is found in the month of August over Mt. Abu region. Figure 7c shows temperature variation in Tropopause region. The Tropopause temperature is extracted from the ERA-Interim atmospheric model and found to be lower than the CIRA-86 and MSISE-90 model tropopause temperatures. Similar kind of trend has been observed over Reunion Island and shown in Fig. 7f. Tropopause temperature is the maximum during September month and we noted reverse trend as compared to Mt. Abu region.

To have further quantitative insight of pauses characteristics, monthly mean temperature differences in tropopause, stratopause and mesopause among SABER (S), CIRA-86 (C) and MSISE-90 (M) have been given in Table 1. In the Mesopause region over Mt. Abu the temperature difference between SABER and MSISE-90 is much higher and found to be maximum during the month of May ( $\sim 16.5 \mathrm{~K})$, whereas CIRA-86 shows higher than SABER observations and the maximum difference observed during January $(\sim 9.3 \mathrm{~K})$. In the Stratopause region, it is seen that the temperature from both the model is higher and maximum difference between SABER and CIRA-86 is $\sim 9.5 \mathrm{~K}$ during the month of April. Similarly, Tropopause temperature is lower than the CIRA-86 and MSISE-90 and maximum difference is found to be $\sim 10.9 \mathrm{~K}$ from MSISE-90 during September, and $\sim 11.6$ from the CIRA-86 during the month of August.

Over Reunion Island, Mesopause temperature revealed minimum difference between SABER and MSISE-90 $(\sim 0.9 \mathrm{~K})$ during January and the maximum difference $(\sim 15 \mathrm{~K})$ is observed in the month of May. The higher temperature observed from CIRA-86 as compared to SABER in this region and the maximum difference in CIRA- 86 and SABER is $\sim 13.3 \mathrm{~K}$ in the month of August. In the Stratopause region, both the models show higher temperature than the SABER temperature. The maximum temperature difference in MSISE-90 and SABER is observed $(\sim 8.2 \mathrm{~K})$ in April. The temperature observed in Mt. Abu region is higher than Reunion Island in Mesopause region during most of the months except during February and November, whereas in the Stratopause region it is lower except during May, June and December months. In the Tropopause region the ERA-Interim temperature is higher during January to April and in December and lower during rest of the months.

\section{Conclusion}

In this study, Tropopause, Stratopause and Mesopause height and temperature are studied at two sub-tropical regions in both hemispheres. Temporal variations of SABER observations during January 2002 to September 2015 are studied extensively. The altitude-temperature profile combined from ERA Interim re-analyses and SABER observations shows mean monthly variation of temperature for different months. As compared to NH, Tropopause height is slightly higher in the SH over Reunion Island. Very small increasing trend in Mesopause and Stratopause height are seen during the study period, which are $\sim 1$ and $\sim 0.7 \mathrm{~km}$ for Mesopause and Stratopause, respectively, in the past 14 years. Though, quantitatively the trends may not be very significant in view of limited vertical resolution, tendency of trends is clear from this extensive study. Temporal variation of temperature shows a very interesting trend, which is decreasing from year 2002 to 2008 (reported by Venkat Ratnam et al. 2010) and beyond this period, an increasing trend is found in temperature at different altitudes. Interestingly, results infer that Mt. Abu and Reunion Island show a cooling trend in Mesopause and that this cooling trend is stronger in the $\mathrm{SH}(-0.14 \mathrm{~K} /$ year) as compared to $\mathrm{NH}(-0.07 \mathrm{~K} /$ year). Results suggest that $\mathrm{SH}$ has a more cooling tendency in Mesopause and Stratopause as compared to $\mathrm{NH}$ in past decade. Results from occurrence frequency patterns suggest that Stratopause is cooler, Mesopause is warmer, in $\mathrm{NH}$ as compared to SH. Moreover, we also used LSP and wavelet transform to find the periodicity of Mesopause, Stratopause and tropopause temperatures and heights. Annual oscillations exist in Tropopause and Stratopause temperature, but these oscillations are not 
observed in Mesopause over both the hemispheres. It is interesting to note here that small period oscillations are more significant in Mesopause height as compared to Stratopause height. Hitherto findings presented in this work on the Tropopause, Stratopause and Mesopause characteristics will significantly contribute to further global investigations on the vertical and inter-hemispheric coupling processes.

\section{Acknowledgements}

Authors are thankful to the scientific, technical and managerial team members of SABER onboard TIMED for providing such a quality global observations of the Erath's middle atmosphere. Our thanks are due to the ERA-Interim reanalysis team members (http://apps.ecmwf.int/). This work is financially supported by Department of Space, Govt. of India.

\section{REFERENCES}

Appenzeller, C., \& Davies, H. C. (1992). Structure of stratospheric intrusions into the troposphere. Nature, 358, 570-572.

Baray, J.L., Gérard, A., Randriambelo, T., Baldy, S. (1999). Tropical cyclone Marlene and stratosphere-troposphere exchange. Journal of Geophysical Research: Atmospheres (1984-2012), 104(D11), 13953-13970.

Berger, U., \& von Zahn, U. (1999). The two-level structure of the Mesopause: a model study. Journal of Geophysical Research: Atmospheres (1984-2012), 104(D18), 22083-22093.

Chandra, H., Som Sharma, Y. B., Acharya, Y. B., \& Jayaraman, A. (2005). A Rayleigh lidar study of the atmospheric temperature structure over Mt. Abu, India. Journal of Indian Geophysical Union, 9(4), 279-298.

Danielsen, E. F. (1968). Stratospheric-tropospheric exchange based on radioactivity, ozone and potential vorticity. Journal of the Atmospheric Sciences, 25(3), 502-518.

Das, S.S. (2009). A new perspective on MST radar observations of stratospheric intrusions into-troposphere associated with tropical cyclone, Geophys. Res. Lett., 36(15).

Dee, D. P., Uppala, S. M., Simmons, A. J., Berrisford, P., Poli, P., Kobayashi, S., et al. (2011). The ERA-interim reanalysis: configuration and performance of the data assimilation system. Quarterly Journal of the Royal Meteorological Society, 137(656), 553-597.

Dunkerton, T. J. (1997). The role of gravity waves in the quasibiennial oscillation. Journal of Geophysical Research: Atmospheres, (1984-2012), 102(D22), 26053-26076.

Gettelman, A., \& Forster, P. M. (2002). A climatology of the tropical tropopause layer. Journal of the Meteorological Society of Japan, 80(4B), 911-924.
Hall, Timothy M., \& Waugh, Darryn. (1997). Tracer transport in the tropical stratosphere due to vertical diffusion and horizontal mixing. Geophysical Research Letters, 24(11), 1383-1386.

Hecht, J.H. (2004). Instability layers and airglow imaging, Reviews of Geophysics, 42(1).

Hitchman, M. H., Gille, J. C., Rodgers, C. D., \& Brasseur, G. (1989). The separated polar winter stratopause: a gravity wave driven climatological feature. Journal of the atmospheric sciences, 46(3), 410-422.

Hocking, W. K., Carey-Smith, T., Tarasick, D. W., Argall, P. S., Strong, K., Rochon, Y., et al. (2007). Detection of stratospheric ozone intrusions by windprofiler radars. Nature, 450(7167), 281-284.

Hoinka, Klaus P. (1998). Statistics of the global tropopause pressure. Monthly Weather Review, 126(12), 3303-3325.

Holton, J. R., Haynes, P. H., McIntyre, M. E., Douglass, A. R., Rood, R. B., \& Pfister, L. (1995). Stratosphere-troposphere exchange. Reviews of geophysics, 33(4), 403-439

Kanzawa, Hiroshi. (1989). Warm stratopause in the antarctic winter. Journal of the atmospheric sciences, 46(3), 435-438.

Kumar, P., Kishtawal, C. M., \& Pal, P. K. (2015). Impact of ECMWF, NCEP, and NCMRWF global model analysis on the WRF model forecast over Indian Region. Theoretical and Applied Climatology. doi:10.1007/s00704-015-1629-1.

Labitzke, Karin. (1977). Interannual variability of the winter stratosphere in the Northern Hemisphere. Monthly Weather Review, 105(6), 762-770.

Labitzke, K. (1981). Stratospheric-mesospheric midwinter disturbances: a summary of observed characteristics. Journal of Geophysical Research: Oceans (1978-2012), 86(C10), 9665-9678.

Labitzke, K., Naujokat., B. (2000). The lower Arctic stratosphere in winter since 1952, SPARC Newsletter, 15.

Li, F., Alan Z.L., Gary R.S. (2005). Characteristics of instabilities in the Mesopause region over Maui, Hawaii, Journal of Geophysical Research: Atmospheres (1984-2012), 110(D9).

Li, T., She, C.Y., Bifford P.W., Tao Y., Richard L.C., Lois M.K., Alan W.P. (2005). Concurrent OH imager and sodium temperature/wind lidar observation of localized ripples over northern Colorado, Journal of Geophysical Research: Atmospheres (1984-2012), 110(D13).

Liu, A.Z., Raymond G.R., James H.H., Miguel F.L., Chester S.G. (2004). Unstable layers in the mesopause region observed with $\mathrm{Na}$ lidar during the Turbulent Oxygen Mixing Experiment (TOMEX) campaign, Journal of Geophysical Research: Atmospheres (1984-2012), 109(D2).

Lomb, N.R. (1976). Least-squares frequency analysis of unequally spaced data, Astrophysics and space science, 39(2), 447-462.

Lübken, F.-J., \& Zahn, U. (1991). Thermal structure of the Mesopause region at polar latitudes. Journal of Geophysical Research: Atmospheres (1984-2012), 96(D11), 20841-20857.

Luo, Y., Manson, A. H., Meek, C. E., Meyer, C. K., Burrage, M. D., Fritts, D. C., et al. (2002). The 16-day planetary waves: multi-MF radar observations from the arctic to equator and comparisons with the HRDI measurements and the GSWM modelling results. Annales Geophysicae, 20(5), 691-709.

McIntyre, Michael E., \& Palmer, T. N. (1983). Breaking planetary waves in the stratosphere. Nature, 305(5935), 593-600.

Meloen, J.P., Siegmund, P. Van Velthoven, H. Kelder, Michiel Sprenger, H. Wernli, A. Kentarchos et al. (2003). Stratospheretroposphere exchange: a model and method intercomparison, 
Journal of Geophysical Research: Atmospheres (1984-2012), 108(D12).

Mertens, C.J., Mlynczak, M.G., Ldpez-Puertas, M., Wintersteiner, P.P., Picard, R.H., Winick, J.R., Gordley, L.L., Russell J.M. (2001). Retrieval of mesospheric and lower thermospheric kinetic temperature from measurements of, Geophysical Research Letters, 28(7), 1391-1394.

Mote, P. W., Karen, H. R., Michael, E. M., Ewan, S. C., John, C. G., James, R. H., et al. (1996). An atmospheric tape recorder: The imprint of tropical tropopause temperatures on stratospheric water vapor. Journal of Geophysical Research: Atmospheres (1984-2012), 101(D2), 3989-4006.

Nakamura, T., Higashikawa, A., Tsuda, T., \& Matsushita, Y. (1999). Seasonal variations of gravity wave structures in $\mathrm{OH}$ airglow with a CCD imager at Shigaraki. Earth, Planets and Space, 51(7-8), 897-906.

Narayana Rao, T., Uma, K.N., Narayana Rao, D., Fukao, S. (2008). Understanding the transportation process of tropospheric air entering the stratosphere from direct vertical air motion measurements over Gadanki and Kototabang, Geophysical Research Letters, 35(15).

Niwano, M., Koji Y., Masato S. (2003). Seasonal and QBO variations of ascent rate in the tropical lower stratosphere as inferred from UARS HALOE trace gas data. Journal of Geophysical Research: Atmospheres (1984-2012), 108(D24).

Prasanth, P. V., Sridharan, S., Kumar, Y. B., Bencherif, H., \& Rao, D. N. (2009). Lidar observations of sodium layer over low latitude, Gadanki $\left(13.5^{\circ} \mathrm{N}, 79.2^{\circ} \mathrm{E}\right)$ : seasonal and nocturnal variations. Annales Geophysicae, 27(10), 3811-3823.

Press, W. H., Flannery, B. P., Teukolsky, S. A., \& Vetterling, W. T. (1992). Numerical recipes in C: The Art of Scientific Computing, vol. 1. Cambridge University Press, Cambridge

Ramaswamy, V., Chanin, M.-L., Angell, J., Barnett, J., Gaffen, D., Gelman, M., et al. (2001). Stratospheric temperature trends: Observations and model simulations. Reviews of Geophysics, $39(1), 71-122$.

Randel, William J., Fei, Wu, Oltmans, Samuel J., Rosenlof, Karen, \& Nedoluha, Gerald E. (2004). Interannual changes of stratospheric water vapor and correlations with tropical tropopause temperatures. Journal of the Atmospheric Sciences, 61(17), 2133-2148.

Remsberg, E.E., Marshall, B.T., Garcia-Comas, M., Krueger, D., Lingenfelser, G.S., Martin-Torres, J., Mlynczak, M.G. et al. (2008). Assessment of the quality of the Version 1.07 temperature-versus-pressure profiles of the middle atmosphere from TIMED/SABER, Journal of Geophysical Research: Atmospheres (1984-2012), 113(D17).

Rosenlof, K. H. (1995). Seasonal cycle of the residual mean meridional circulation in the stratosphere. Journal of Geophysical Research: Atmospheres, 100(D3), 5173-5191.

Russell, J.M. III, Martin G.M., Gordley, L.L., Tansock J., Esplin, R. (1999). Overview of the SABER experiment and preliminary calibration results, In SPIE's International Symposium on Optical Science, Engineering, and Instrumentation, International Society for Optics and Photonics, 277-288.

Sarkhel, S., Sekar, R., Chakrabarty, D., Narayanan, R., Sridharan, S. (2009a). Simultaneous sodium airglow and lidar measurements over India: A case study, Journal of Geophysical Research: Space Physics (1978-2012), 114(A10).

Sarkhel, S., Sekar, R., Chakrabarty, D., Narayanan, R., Sridharan, S. (2009b). Simultaneous sodium airglow and lidar measurements over India: a case study, Journal of Geophysical Research: Space Physics (1978-2012), 114(A10).

Scargle, Jeffrey D. (1982). Studies in astronomical time series analysis. II-Statistical aspects of spectral analysis of unevenly spaced data. The Astrophysical Journal, 263, 835-853.

Sharma, S., Sivakumar, V., Bencherif, H., Chandra, H., Acharya, Y. B., Jayaraman, A., et al. (2006). A comprehensive study on middle atmospheric thermal structure over a tropic and sub-tropic stations. Advances in Space Research, 37(12), 2278-2283.

Sharma, S., Sridharan, S., Chandra, H., Lal, S., \& Acharya, Y. B. (2012). Middle atmospheric thermal structure over sub-tropical and tropical Indian locations using Rayleigh lidar. Planetary and Space Science, 63, 36-48.

She, C.Y., Tao L., Bifford P.W., Tao Y., Picard, R.H. (2004). Concurrent $\mathrm{OH}$ imager and sodium temperature/wind lidar observation of a Mesopause region undular bore event over Fort Collins/Platteville, Colorado, Journal of Geophysical Research: Atmospheres (1984-2012), 109(D22).

She, C. Y., Yu, J. R., \& Chen, H. (1993). Observed thermal structure of a midlatitude Mesopause. Geophysical Research Letters, 20(7), 567-570.

Sivakumar, V., Vishnu Prasanth, P., Kishore, P., Bencherif, H., Keckhut, P. (2011). Rayleigh LIDAR and satellite (HALOE, SABER, CHAMP and COSMIC) measurements of stratospheremesosphere temperature over a southern sub-tropical site, Reunion $\left(20.8^{\circ} \mathrm{S} ; 55.5^{\circ} \mathrm{E}\right)$ : climatology and comparison study, Annales Geophysicae, 29(4).

Škerlak, B., Sprenger, M., \& Wernli, H. (2014). A global climatology of stratosphere-troposphere exchange using the ERAInterim data set from 1979 to 2011. Atmospheric Chemistry and Physics, 14(2), 913-937.

Tang, Yihuan, Dou, Xiankang, Li, Tao, Nakamura, Takuji, Xue, Xianghui, Huang, Can, et al. (2014). Gravity wave characteristics in the Mesopause region revealed from $\mathrm{OH}$ airglow imager observations over Northern Colorado. Journal of Geophysical Research: Space Physics, 119(1), 630-645.

Taylor, M. J., Pendleton, W. R., Jr., Clark, S., Takahashi, H., Gobbi, D., \& Goldberg, R. A. (1997). Image measurements of short period gravity waves at equatorial latitudes. Journal of geophysical research, 102(D22), 26283.

Thompson, D. W. J., Baldwin, M. P., \& Wallace, J. M. (2002). Stratospheric connection to Northern Hemisphere wintertime weather: implications for prediction. Journal of Climate, 15(12), 1421-1428.

Venkat Ratnam, M., Patra, A.K., Krishna Murthy, B.V. (2010). Tropical Mesopause: is it always close to $100 \mathrm{~km}$ ?, Journal of Geophysical Research: Atmospheres (1984-2012), 115(D6).

Walterscheid, R. L., Hecht, J. H., Vincent, R. A., Reid, I. M., Woithe, J., \& Hickey, M. P. (1999). Analysis and interpretation of airglow and radar observations of quasi-monochromatic gravity waves in the upper mesosphere and lower thermosphere over Adelaide, Australia (35 S, 138 E). Joumal of Atmospheric and Solar-Terrestrial Physics, 61(6), 461-478.

Waugh, D. W., William, J. R., Steven, P., Paul, A. N., \& Eric, R. N. (1999). Persistence of the lower stratospheric polar vortices. Journal of Geophysical Research: Atmospheres (1984-2012), 104(D22), 27191-27201.

Williams, B.P., White, M.A., Krueger, D.A., She, C.Y. (2002). Observation of a large amplitude wave and inversion layer leading to convective instability in the Mesopause region over 
Fort Collins, CO (41 N, $105 \mathrm{~W})$, Geophysical research letters, 29(17), 31-1.

Xu, J., She, C.Y., Yuan, W., Mertens, C., Mlynczak, M., Russell, J. (2006). Comparison between the temperature measurements by TIMED/SABER and lidar in the midlatitude, Journal of Geophysical Research: Space Physics (1978-2012), 111(A10).

Yee, J.H., Glen E.C., David Y.K. (1999). Overview of TIMED, In: SPIE's International Symposium on Optical Science,
Engineering, and Instrumentation, International Society for Optics and Photonics, 244-254.

Yulaeva, Elena, Holton, James R., \& Wallace, John M. (1994). On the cause of the annual cycle in tropical lower-stratospheric temperatures. Journal of the atmospheric sciences, 51(2), 169-174. 